\title{
Meningoencefalite por Herpesvirus bovino 5 em Minas Gerais: relato de caso clínico
}

[Meningoencephalitis by Bovine herpesvirus 5 in Minas Gerais state: clinical case report]

\author{
H.M. Aquino Neto ${ }^{1}$, A.U. Carvalho ${ }^{2}$, E.J. Facury Filho ${ }^{2 *}$, P.M. Ferreira ${ }^{2}$, E.F. Barbosa-Stancioli ${ }^{3}$, \\ Z.I.P. Lobato ${ }^{2}$, M.R. Alvarenga ${ }^{4}$, A.L. Serrano ${ }^{5}$, R.A. Martins ${ }^{5}$, D.A.F. Afonso ${ }^{6}$ \\ ${ }^{1}$ Aluno pós-graduação - EV-UFMG - Belo Horizonte, MG \\ ${ }^{2}$ Escola de Veterinária - UFMG \\ Caixa Postal 567 \\ 30123-970 - Belo Horizonte, MG \\ ${ }^{3}$ Instituto de Ciências Biológicas - UFMG - Belo Horizonte, MG \\ ${ }^{4}$ Curso de Medicina Veterinária - PUC-Minas - Betim, MG \\ ${ }^{5}$ Aluno de graduação - EV-UFMG - Belo Horizonte, MG \\ ${ }^{6}$ Aluno de pós-graduação - ICB-UFMG - Belo Horizonte, MG
}

\section{RESUMO}

Relata-se um caso de meningoencefalite causada por Herpesvirus bovino 5 (BoHV-5) heritabilityem uma vaca com cinco anos de idade. $\mathrm{O}$ animal manifestou quadro clínico inicial de síndrome medular baixa, caracterizada por incoordenação dos membros pélvicos, sinais estes ainda não descritos para a enfermidade. Dentro de pouco tempo a doença evoluiu para síndrome cerebral, e o óbito ocorreu seis dias após o inicio dos sintomas. Na histopatologia, evidenciou-se meningoencefalite difusa, não supurada, e a confirmação do diagnóstico foi feita por reação em cadeia de polimerase e sequenciamento do segmento parcial da glicoproteína $G$ do vírus. O trabalho confirma a presença do BoHV-5 em Minas Gerais, descreve características clínicas novas para a enfermidade e ressalta sua importância no diagnóstico diferencial das neuropatias bovinas.

Palavras-chave: bovino, herpesvirus, meningoencefalite, neuropatia

\begin{abstract}
A clinical case of meningoencephalitis by Bovine herpesvirus 5 (BoHV-5) in a five-year-old cow was reported. The disease began with low spinal cord signs, characterized by incoordination, and these symptoms had never been related to this illness before. Signs of a brain syndrome were observed and the cow died in six days. At the histopathology, a spread non-supurative meningoencephalitis was diagnosed, and the virus identification was made by PCR and partial sequence of the glycoprotein G. This study confirm the BoHV-5 presence in the State of Minas Gerais, Brazil, describes new clinic characteristics, and show the importance of the disease in the differentiate diagnosis with others bovine central nervous system affections.
\end{abstract}

Keywords: bovine, herpesvirus, meningoencephalitis, neuropathy

\section{INTRODUÇÃO}

Os distúrbios neurológicos em bovinos abrangem um grupo de enfermidades muito importantes, tanto pelo perigo em potencial que representam para a saúde humana, quanto pelas expressivas perdas econômicas que ocasionam. Dois aspectos importantes envolvem as neuropatias: frequência e dificuldade de diagnóstico, esta última ligada à variação de manifestação clínica de uma mesma doença, à semelhança sintomatológica existente entre algumas delas e, em vários casos, à falta de estrutura técnica dos laboratórios para diagnóstico.

Recebido em 6 de março de 2008

Aceito em 29 de outubro de 2008

*Autor para correspondência (corresponding author)

E-mail: facury@vet.ufmg.br 
Dentre as neuropatias, uma ainda pouco conhecida, porém muito estudada nos últimos anos é a meningoencefalite causada por Herpesvirus bovino 5 (BoHV-5). A doença tem sido observada nas Américas do Sul e do Norte (Riet-Correa et al., 1989; D’Offay et al., 1993; Pérez et al., 2003) e, esporadicamente, em outros países como Austrália (Hill et al., 1984), Hungria (Bartha et al., 1969), Itália (Moretti et al., 1964) e Escócia (Watt et al., 1981). No Brasil, já foram descritos surtos em alguns estados das regiões Centro-Oeste (De Paula et al., 2005), Sudeste (Gomes et al., 2002), Sul (Riet-Correa et al., 1989) e Norte (Riet-Correa et al., 2006). A baixa frequência de relatos da enfermidade decorre principalmente da dificuldade da realização do diagnóstico diferencial entre as enfermidades que afetam o sistema nervoso central dos bovinos e da semelhança na sintomatologia neurológica, que dificulta a interpretação dos achados e induz diagnósticos equivocados.

$\mathrm{O}$ presente relato tem como objetivo descrever um caso de meningoencefalite por BoHV-5 em que os sintomas apresentaram características distintas das frequentemente descritas para a enfermidade.

\section{CASUÍSTICA}

Uma fêmea bovina mestiça, de cinco anos de idade, oriunda do município de Mutum, MG, deu entrada no Hospital Veterinário da Universidade Federal de Minas Gerais apresentando quadro inicial de neuropatia. A propriedade da qual o animal é proveniente, explora a bovinocultura leiteira e possuía, naquele período, 140 vacas em lactação, manejadas em sistema semi-intensivo. O rebanho foi vacinado contra febre aftosa, brucelose e clostridioses. Seis meses antes, morreram quatro vacas, com intervalo de poucas semanas, manifestando incoordenação motora, andar rígido e espasmos musculares. O material de dois desses animais, encaminhado para diagnóstico de raiva, foi negativo. A histologia cerebral revelou meningoencefalite não supurada. O curso da doença na fazenda variou de três a cinco dias, sendo que, nas últimas 30 horas os animais não conseguiam mais se levantar e apresentavam opistótono e movimentos de pedalagem.

Segundo o veterinário responsável pela propriedade, o animal foi encaminhado para o hospital veterinário no mesmo dia de manifestação dos primeiros sintomas, caracterizados por leves tremores musculares e incoordenação motora.

Ao exame clínico, observaram-se excitação, estação com membros posteriores abduzidos, levemente deslocados para frente e com frequente troca de apoio entre os mesmos, escore corporal três, condição física regular, discretos tremores musculares, especialmente na região da cabeça, escápula e membros pélvicos, reflexo pupilar diminuído e midríase, além de rúmen repleto, com conteúdo fibroso e movimentos de baixa intensidade. $\mathrm{O}$ apetite estava presente, com preensão, mastigação e deglutição normais. $\mathrm{O}$ animal apresentava dificuldade de locomoção devido à incoordenação dos membros pélvicos, além de constante troca de apoio entre os membros. Na evolução, não apresentou alterações consideráveis nos parâmetros vitais, porém continuou excitado e demonstrou progressiva dificuldade de manter-se de pé e de locomover-se. No quarto dia, evoluiu para decúbito esternal e, no quinto, para lateral. Nesse momento, observou-se diminuição na acuidade visual. A partir daí, manifestou sensibilidade superficial e profunda diminuídas, fezes ressecadas formando síbalas, espasmos musculares, opistótono, bruxismo e movimentos contínuos de abrir e fechar a boca. O óbito ocorreu no sexto dia após o início dos sintomas.

À necropsia, não se observaram achados macroscópicos significativos. Fragmentos de encéfalo (hipocampo, tronco encefálico, cerebelo), gânglio trigeminal e medula espinhal foram colhidos em duas alíquotas e conservados sob refrigeração para serem submetidos à pesquisa de vírus (raiva e BoHV-5). Efetuou-se clap e squash cerebrais, para pesquisa de hemoparasitas. O restante do encéfalo foi fixado em formalina tamponada a 10\%, para exame histológico. Após 24 horas de fixação, fragmentos de córtex, tálamo, núcleos da base, colículos, pedúnculos cerebelares, cerebelo, óbex e medula foram coletados, e acondicionados em cassetes.

A histopatologia revelou meningoencefalite não supurada difusa, caracterizada por manguitos perivasculares, constituídos principalmente por linfócitos e macrófagos. Não foram observadas áreas de malacia ou corpúsculos de inclusão 
intranucleares em células nervosas. O clap e o squash cerebrais foram negativos para hemoparasitas, e o exame de raiva também apresentou resultado negativo. Baseando-se nos achados histológicos, no teste da reação da polimerase em cadeia (PCR) e sequenciamento do amplicon amplificado, foi possível chegar ao diagnóstico de meningoencefalite por BoHV-5. A amostra de BoHV-5 do referido caso foi nomeada como Mutum e o segmento parcial da glicoproteína $\mathrm{G}$ do vírus foi sequenciado $\mathrm{e}$ depositado no GenBank, com número de acesso AY916517.

\section{DISCUSSÃO}

A metodologia de trabalho para o estabelecimento do diagnóstico baseou-se em uma investigação minuciosa de todos os dados levantados, seguidos de montagem e interpretação. De acordo com a anamnese, vinha ocorrendo mortalidade esporádica em animais adultos, caracterizada por neuropatia. O quadro clínico iniciou-se com síndrome medular baixa, com sintomas de incoordenação dos membros pélvicos, e evoluiu para síndrome cortical. A ausência de lesões macroscópicas à necropsia e a presença de meningoencefalite não supurada na histologia do sistema nervoso central (SNC), com manifestação de um quadro neurológico, são sugestivos de uma infecção viral. Partindo dessa suspeita, os fragmentos de SNC foram encaminhados para o diagnóstico de raiva e pesquisa de BoHV-5. O resultado negativo para raiva, associado à epidemiologia, quadro clínico, histopatologia e detecção do BoHV-5 na amostra, permitiu diagnosticar, com exatidão, o caso clínico como uma meningoencefalite por Herpesvirus bovino 5.

De acordo com os primeiros relatos de meningoencefalite por BoHV-5 no Brasil, a doença acometia principalmente bezerros com menos de um mês de idade (Riet-Correa et al., 1989; Weiblen et al., 1989), bovinos recémdesmamados (Riet-Correa e Schild, 1995 citado por Quincozes, 2005), ou com até dois anos e meio de idade (Vasconcelos et al., 1993). No presente caso, o animal manifestou sintomatologia clínica aos cinco anos de idade, achado este que confirma as citações de Salvador et al. (1998), ao verificarem que a doença acometeu animais de uma ampla faixa etária (seis a 60 meses) no Mato Grosso do Sul, assim como um estudo retrospectivo realizado por Botelho (2000), em amostras parafinadas de SNC, provenientes dos Estados de Minas Gerais e Espírito Santo, onde a idade dos bovinos afetados variou de cinco meses a cinco anos.

$\mathrm{O}$ animal era manejado em sistema semiintensivo, aspecto também observado na maioria dos surtos ocorridos em território nacional (RietCorrea et al., 1989; Salvador et al., 1998; Elias et al., 2004). Em surtos descritos em outros países, a doença é mais comum em rebanhos de criação intensiva, nos quais ocorre aglomeração de animais de diversas origens (George, 1991).

O curso da doença descrita foi de seis dias, o que está dentro dos períodos observados por outros autores, que citam um intervalo de quatro a 15 dias, com a maioria das mortes ocorrendo entre um e seis dias (Riet-Correa et al., 1989; Salvador et al., 1998; Elias et al., 2004).

$\mathrm{O}$ achado histopatológico mais frequente é uma meningoencefalite não supurativa, normalmente difusa, algumas vezes acompanhada de malacia, variando quanto à localização e intensidade em cada caso (Salvador et al., 1998; Colodel et al., 2002; Elias et al., 2004; Pedraza e Alessi, 2004; Rissi et al., 2006). Inclusões intranucleares eosinofílicas em astrócitos e neurônios podem aparecer em maior ou menor frequência (George, 1991; Ely et al., 1996; Salvador et al., 1998; Elias et al., 2004; Rissi et al., 2006), ou ocasionalmente não serem encontradas (Barenfus et al., 1963; Carrillo et al., 1983). Essas inclusões são mais comumente observadas em áreas de inflamação e malacia (Colodel et al., 2002; Elias et al., 2004; Rissi, et al., 2006). No caso descrito neste trabalho, não foram evidenciadas lesões de malacia ou corpúsculos de inclusão no material analisado, alterações que, embora frequentes, não estão necessariamente presentes em todos os casos. Esse fato pode ser atribuído às diferenças de neurovirulência entre amostras de BoHV-5 (Beltrão et al., 2000; Caron et al., 2002).

O encaminhamento do animal para o hospital veterinário com quadro inicial de meningoencefalite por BoHV-5 e seu acompanhamento clínico diário permitiram a observação de alguns sintomas que não são descritos normalmente para essa doença. Os sinais de síndrome medular baixa, caracterizada por incoordenação e troca frequente de apoio 
entre os membros pélvicos, que progressivamente evoluiu para um quadro cerebral, são bastante incomuns. Sinais medulares, como os observados neste caso, seriam raros principalmente em decorrência da via de acesso do vírus ao SNC, através das fibras nervosas distribuídas na mucosa nasal (McKercher et al., 1970), especialmente do bulbo olfatório e nervo trigêmeo (Beltrão et al., 2000; Meyer et al., 2001; Caron et al., 2002) e, desse modo, a doença já se instalaria com sintomas cerebrais, como descrito na maioria dos relatos.

O isolamento da amostra Mutum de BoHV-5 do bovino com sintomas medulares permite refletir sobre a probabilidade de que o vírus possa, de alguma maneira, atingir a medula espinhal. Uma das questões levantadas seria que esses sintomas poderiam ocorrer naturalmente, porém são de difícil observação, porque muitas vezes os animais são encontrados em fase terminal, quando a assistência veterinária é solicitada, e pelo fato de a doença manifestar-se de forma esporádica, dificultando o acompanhamento clínico de vários casos, simultaneamente. Outra hipótese seria a de que o isolado Mutum, especificamente, tivesse maior facilidade de atingir a medula.

Até o momento, quatro amostras parafinadas de SNC (Botelho, 2000) provenientes de surtos de neuropatia envolvendo animais com oito meses, três e cinco anos de idade, nos anos de 1988, 1993 e 1995, respectivamente, e três amostras congeladas de SNC (Gomes et al., 2002) são os únicos casos descritos da infecção pelo BoHV-5 em Minas Gerais. O presente relato confirma a presença do vírus no estado, causando um quadro clínico com algumas características próprias e distintas das observadas em outras regiões do Brasil. Além disso, a meningoencefalite por BoHV-5, como descrita neste trabalho, apresenta sintomas e curso similares aos da raiva, doença endêmica em Minas Gerais, responsável pelo maior número de diagnósticos dentre as neuropatias. Dessa forma, a enfermidade causada pelo BoHV-5 constitui um dos principais diagnósticos diferenciais da raiva bovina $\mathrm{e}$ demanda estudos de sua epidemiologia, apresentação clínica e diagnóstico. É de fundamental importância, no diagnóstico das neuropatias, a realização de um exame clínico criterioso, metódico, assim como a coleta e a remessa adequadas de material para laboratório. Associando-se às informações epidemiológicas os achados clínicos, de necropsia e o resultado dos exames complementares, é possível o estabelecimento do diagnóstico.

\section{REFERÊNCIAS BIBLIOGRÁFICAS}

BARENFUS, M.; DELLIQUADRI, C.A.; McINTYRE, R.W. et al. Isolation of infectious bovine rhinotracheitis virus from calves with meningo-encephalitis. J. Am. Vet. Med. Assoc., v.143, p.725-728, 1963.

BARTHA, A.; HADJU, G.; AIDASY, P. et al. Ocurrence of encephalitis caused by infectious rhinotracheitis virus in calves in Hungary. Acta Vet. Hung., v.19, p.145-151, 1969.

BELTRÃO, N.; FLORES, E.F.; WEIBLEN, R. et al. Infecção e enfermidade neurological por Herpesvirus bovino 5 (BHV-5): coelhos como modelo experimental. Pesq. Vet. Bras., v.20, p.144-150, 2000.

BOTELHO, R.G.A. Desenvolvimento de testes de PCR para BoHV-5 e sua aplicação no diagnóstico de casos clínicos. 2000. 45f. Dissertação (Mestrado) - Escola de Veterinária, Universidade Federal de Minas Gerais, Belo Horizonte.

CARON, L.; FLORES, E.F.; WEIBLEN, R. et al. Latent infection by Bovine herpesvirus type-5 in experimentally infected rabbits: virus reactivation, shedding and recrudescence of neurological disease. Vet. Microbiol., v.84, p.285-295, 2002.

CARRILLO, B.J.; POSPISCHIL, A.; DAHME, E. Pathology of a bovine virus necrotizing encephalitis in Argentina. Zentbl. Vet. Med. B, v.30, p.161-168, 1983.

COLODEL, M.E.; NAKAZATO, L.; WEIBLEN, R. et al. Meningoencefalite necrosante em bovinos causada por herpesvírus bovino no estado do Mato Grosso, Brasil. Cienc. Rural, v.32, p.293-298, 2002.

D’OFFAY, J.M.; MOCK, R.E.; FULTON, R.W. Isolation and characterization of encephalitic bovine herpesvirus type 1 isolates from cattle in North America. Am. J. Vet. Res., v.54, p.534$539,1993$.

DE PAULA, R.R.; SOUZA, M.A.; COLODEL, E.M. et al. Meningoencefalite causada pelo 
BHV-5 em um bovino no estado de Goiás. Arq. Bras. Med. Vet. Zootec., v.57, supl. 1, p.2, 2005.

ELIAS, F.; SCHILD, A.L.; RIET-CORREA, F. Meningoencefalite e encefalomalácia por herpesvírus bovino - 5: distribuição das lesões no sistema nervoso central de bovinos naturalmente infectados. Pesq. Vet. Bras., v.24, p.123-131, 2004.

ELY, R.W.; D’OFFAY, J.M.; RUEFER, A.H. et al. Bovine herpesviral encephalitis: a retrospective study on archived formalin-fixed, paraffin-embedded brain tissue. J. Vet. Diagn. Invest., v.8, p.487-492, 1996.

GEORGE, L.W. Understanding the encephalitic form of infectious bovine-rhinotracheitis. Vet. Med., v.86, p.335-337, 1991.

GOMES, L.I.; ROCHA, M.A.; COSTA, E.A. et al. Detecção de herpesvírus bovino 5 (BoHV-5) em bovinos no sudeste brasileiro. Arq. Bras. Med. Vet. Zootec., v.54, p.217-220, 2002.

HILL, B.D.; HILL, M.W.M.; CHUNG, Y.S. et al. Meningoencephalitis in calves due to bovine herpesvirus type 1 infection. Aust. Vet. J., v.61, p.242-243, 1984.

McKERCHER, D.G.; BIBRACK, B.; RICHARDS, W.P.C. Effects of the infectious bovine rhinotracheitis virus on the central nervous system of cattle. J. Am. Vet. Med. Assoc., v.156, p.1460-1467, 1970.

MEYER, G.; LEMAIRE, M.; ROS, C. et al. Comparative pathogenesis of acute and latent infections of calves with bovine herpesvirus types 1 and 5. Arch. Virol., v.146, p.633-652, 2001.

MORETTI, B.; ORFEI, Z.; MONDINO, G. et al. Infectious bovine rhinotracheitis clinical observations and isolation of virus. Vet. Ital., v.15, p.676, 1964.

PEDRAZA, F.J.; ALESSI, A.C. Encefalitis bovina por herpesvirus bovino tipo 5 (HVB-5). Una revisión. Rev. Col. Cienc. Pec., v.17, p.148155, 2004.

PÉREZ, S.E.; VAGNOZZI, A.; SUR, J.H. et al. Retrospective analysis of cases with a diagnosis of cerebrocortical necrosis and its relation with type 5 bovine herpesvirus. Rev. Arg. Microbiol., v.35, p.69-73, 2003.

QUINCOZES, C.G. Prevalência e fatores de risco associados às infecções pelos herpesvírus bovino tipo 1 e 5 ( $B H V-1$ e 5) e pelo vírus $d a$ diarréia viral bovina (BVDV) nos rebanhos dos municípios de Santa Vitória do Palmar e Chuí. 2005. 103f. Dissertação (Mestrado) Universidade Federal de Pelotas, Pelotas.

RIET-CORREA, F.; VIDOR, T.; SCHILD, A.L. et al. Meningoencefalite e necrose do córtex cerebral em bovinos causadas por herpesvírus bovino 1. Pesq. Vet. Bras., v.9, p.13-16, 1989.

RIET-CORREA, F.; SCHILD, A.L. Doenças diagnosticados pelo Laboratório Regional de Diagnóstico no ano de 1994 e comentários sobre algumas doenças. Bol. Lab. Reg. Diagn., v.15, p.7-19, 1995.

RIET-CORREA, G.; DUARTE, M.D.; BARBOSA, J.D. et al. Meningoencefalite e polioencefalomalácia causadas por herpesvírus bovino-5 no estado do Pará. Pesq. Vet. Bras., v.26, p.44-46, 2006.

RISSI, D.R.; OLIVEIRA, S.N.; RECH, R.R. et al. Epidemiologia, sinais clínicos e distribuição das lesões encefálicas em bovinos afetados por meningoencefalite por herpesvírus bovino-5. Pesq. Vet. Bras., v.26, p.123-132, 2006.

SALVADOR, S.C.; LEMOS, R.A.A.; ROEHE, P.M. Meningoencefalite em bovinos causada por herpesvírus bovino 5 no Mato Grosso do Sul e São Paulo. Pesq. Vet. Bras., v.18, p.76-83, 1998.

VASCONCELOS, R.O.; VARASCHIN, N.S.; WOUTERS, F. et al. Meningoencefalite bovina por herpesvírus. In: ENCONTRO NACIONAL DE PATOLOGIA VETERINÁRIA, 6., 1993, Santa Maria. Anais... Santa Maria, 1993, p.11.

WATT, J.A.; JONSTON, W.S.; BARLOW, R.M. Infectious bovine rhinotracheitis and encephalitis. Vet. Rec., v.108, p.63, 1981.

WEIBLEN, R.; LOMBARRO, C.B.S.; CANABARRO, T.F. et al. Bovine meningoencephalitis from IBR virus. Vet. Rec., v. 124, p. 666-667, 1989. 